\title{
Excess winter mortality and morbidity before, during, and after the Great Recession: the Portuguese case
}

\author{
Ricardo Almendra ${ }^{1}$ (D) Julian Perelman ${ }^{2} \cdot$ Joao Vasconcelos $^{3} \cdot$ Paula Santana $^{4}$
}

Received: 26 July 2018 / Revised: 7 February 2019 / Accepted: 18 February 2019 / Published online: 7 March 2019

(C) ISB 2019

\begin{abstract}
Although winter mortality and morbidity are phenomena common to most European countries, their magnitude varies significantly from country to country. The geographical disparities among regions with similar climates are the result of several social, economic, demographic, and biological conditions that influence an individual's vulnerability to winter conditions. The impact of poor socioeconomic conditions may be of such magnitude that an economic recession may aggravate the seasonal mortality pattern. This paper aims to measure the seasonal winter mortality, morbidity, and their related costs during the Great Recession (2009-2012) in mainland Portugal and its Regional Health Administrations (RHAs) and to compare it with the periods preceding and following it. Monthly mortality and morbidity data were collected and clustered into three periods: Great Recession (20092012), Pre-Recession (2005-2008), and Post-Recession (2013-2016). The impact of seasonal winter mortality and morbidity during the Great Recession in Portugal and its Regional Health Administrations was measured through the assessment of agestandardized excess winter (EW) death and hospital admissions rate and index, expected life expectancy gains without EW deaths, EW rate of potential years of life lost, and EW rate of emergency hospital admission costs. Important increases of winter deaths and hospital admissions were identified, resulting in an important number of potential years of life lost (87 years of life lost per 100,000 inhabitants in 2009-2012), life expectancy loss (1 year in 2009-2012), and National Health Service costs with explicit temporal and spatial variations. These human and economic costs have decreased consistently during the analyzed periods, while no significant increase was found during the Great Recession. Despite its reduction, the winter excess morbidity and mortality highlight that Portugal still faces substantial challenges related to a highly vulnerable population, calling for investments in better social and health protection.
\end{abstract}

Keywords Excess winter mortality $\cdot$ Excess winter morbidity $\cdot$ Great Recession $\cdot$ Economic crisis

Ricardo Almendra

Ricardoalmendra85@gmail.com

Julian Perelman

JPerelman@ensp.unl.pt

Joao Vasconcelos

joaovvasconcelos@gmail.com

Paula Santana

paulasantana.coimbra@gmail.com

1 Centre of Studies in Geography and Spatial Planning, University of Coimbra, Coimbra, Portugal

2 Escola Nacional de Saúde Pública, Universidade Nova de Lisboa, Lisbon, Portugal

3 Polytechnic Institute of Leiria, IGOT/CEG Universidade de Lisboa, Lisbon, Portugal

4 Centre of Studies on Geography and Spatial Planning, Department of Geography, University of Coimbra, Coimbra, Portugal

\author{
Abbreviations \\ RHA Regional Health Administrations \\ EW Excess winter \\ NHS National Health Service \\ LVT Lisboa e Vale do Tejo \\ PYLL Potential years of life lost
}

\section{Background}

The monthly distribution of mortality throughout the yeari.e., the so-called seasonal behavior - is well-known, and is generally characterized by a winter peak, often referred to as excess winter (EW) mortality (Dimitriou et al. 2016). A relationship between socioeconomic conditions and excess winter mortality is often found (Healy 2003). The impact of poor socioeconomic conditions may be of such magnitude that an 
economic recession may aggravate the seasonal mortality pattern.

Most of EW mortality is related to diseases of the circulatory and respiratory system (Rau 2004; Antunes et al. 2017). Exposure to low temperatures can have severe biological consequences, producing changes in blood pressure, causing vasoconstriction, and increasing the levels of plasma fibrinogen and cholesterol (Mercer 2003; Sartini et al. 2016), while the inhalation of cold air is related to higher risk of bronchitis, pneumonia, and acute exacerbation of chronic lung diseases (Ou et al. 2013). The consequences of the exposure to harmful weather conditions are greater in older people (Rudge and Gilchrist 2005; Benmarhnia et al. 2014) where the overlapping of biological and social fragility is frequent.

Despite being common to most European countries, the EW mortality spatial pattern is heterogeneous (Keatinge 1997). In regions with harsher winters, individuals may benefit from a better protective attitude towards cold weather and a better adapted built environment; therefore, despite the evidence of the biological effects of cold on human health, the fact that the seasonality of the diseases is more evident in areas with mild climate suggests that EW mortality is strongly associated with socioeconomic determinants (Davie et al. 2007). Healy (2003) identified a positive association, at country level, between EW mortality and income measures, such as estimated gross domestic product based on purchasing power parity.

Portugal is one of the European countries with higher EW mortality (Healy 2003; Fowler et al. 2015; Liddell et al. 2016); the seasonal mortality patterns are often characterized by important winter increases (Pinheiro 1990; Freire 1996; Nogueira and Paixão 2007; Almendra et al. 2016, 2017). Among the conditions most often referred to justify geographical differences in the vulnerability to winter cold weather are those related to poverty and its consequences, such as deprivation (Healy 2003; Almendra et al. 2017), poor housing conditions (Healy 2003; Almendra et al. 2017), fuel poverty (Hajat et al. 2006), or limited access to healthcare services (Hales et al. 2012).

Portuguese social and economic structures were among the most hardly shaken by the Great Recession, which, in accordance with the technical definition of recessions (two quarters of negative growth), lasted from 2009 to 2011. Those years of economic recession had severe consequences, such as strong unemployment increases (from $8.8 \%$ in 2008 to $15.8 \%$ in 2012) (Perelman et al. 2015), loss of purchasing power, and important emigration flows (136,615 registered emigrants between 2009 and 2012). In 2011, with the introduction of the Economic Adjustment Programme, an agreement to implement several reforms, the often mentioned "austerity measures," was established to reduce public expenditures (including those in the National Health Service (NHS)) (European Commission 2014). It has been mentioned that this bail-out program might have had important impacts on healthcare provision, leading to increasing health inequalities, barriers to access to health services, especially for vulnerable groups, such as the elderly (Doetsch et al. 2017).

Also, it may be hypothesized that the deterioration of socioeconomic conditions and greater impoverishment of the population most likely contributed to an aggravation of an individual's vulnerability to cold weather given how they change the complex combination of physiological, social, and cultural adaptation factors to harmful temperatures (Hales et al. 2012; Benmarhnia et al. 2014): hence, the drop in income during the Great Recession could have influenced the ability to intervene in the environment where people live (e.g., inability to improve the housing conditions or keep them warm), and the NHS cuts may be affecting the utilization of hospital services (Perelman et al. 2015). Regardless of economic circumstances, biological vulnerability may also be growing due to the aging trend of Portuguese population.

The assessment of the health impacts of the Great Recession is an important topic among Public Health researchers (Perelman et al. 2015; Tapia Granados and Rodriguez 2015). However, the results obtained seem to be somehow contradictory, varying from the identification of significant harmful consequences of the economic recession in healthcare provision (Legido-Quigley et al. 2016) and health outcomes (Benmarhnia et al. 2014), in particular those related to mental health (Karanikolos et al. 2013; Frasquilho et al. 2015), to some "protective effect," particularly in mortality indicators (Regidor et al. 2014; Tapia Granados and Rodriguez 2015).

The impact of the economic crisis in the seasonal mortality pattern was addressed in Spain by Benmarhnia et al. (2014), but a study assessing the EW mortality and morbidity toll in Portugal is still missing, despite being recognized as one of the European countries with higher EW mortality. Thus, this paper aims to (i) measure the seasonal winter mortality, morbidity, and its related costs during the Great Recession (20092012) in mainland Portugal and its Regional Health Administrations (RHAs) and (ii) compare it with the 4-year period that preceded (2005-2008) and followed it (20132016).

\section{Data and methods}

\section{Study area}

Mainland Portugal (hereafter referred to as Portugal) is located in Western Europe (Fig. 1) in a transitional region between the subpolar depression zones in north and the sub-tropical anticyclone area in the south. Mean monthly air temperature values vary regularly during the year, reaching their maximum in August and minimum in January. According to the 


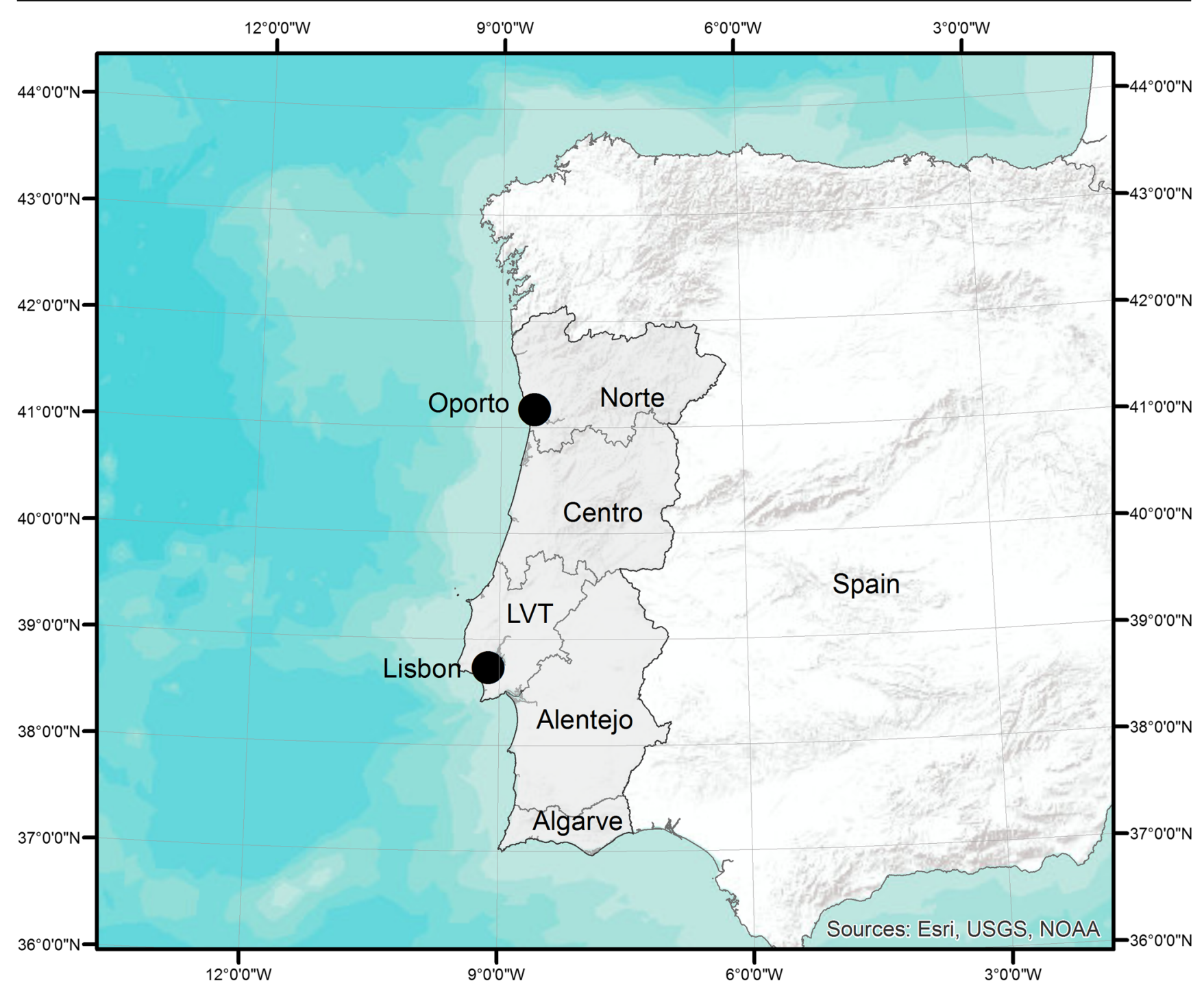

Fig. 1 Location of the study area

Köppen-Geiger classification, it has a typical Mediterranean climate with mild, wet winters, and warm and dry summers (Csa in the South and Csb in the North). During the period under analysis, nine winters were colder than normal and three warmer; 2016 was the warmest winter and 2005 the coldest (the years represented by the dots cluster information of January and February months and December from previous year) (Fig. 2).

In accordance with the Statistics Portugal, Portugal has a population of nearly 10 million, the majority of which lives in the coastal area and the two most populous cities, Lisbon and Oporto, which account for 4.5 million inhabitants.

Decree-Law 11/93 of 15 January indicates that the Portuguese National Health Service is organized in five RHAs (Norte, Centro, Lisboa e Vale do Tejo (LVT), Alentejo, and Algarve), which are legally distinct entities, executing their own functions of planning, distribution of resources, administration and coordination of activities, human resources management, technical, and administrative support. However, the Portuguese NHS is very centralized so that RHAs have in practice little autonomy. The RHAs were used in this study because they reflect relevant socio-demographic differences within the country.

In 2011, Alentejo was the region with highest aging index (189.2) and Norte with the lowest (114.1); the number of official public hospitals beds per inhabitant was largest in Centro (3.2) and lowest in Algarve (1.9); LVT had the highest upper secondary education rate $(43.8 \%)$ and Norte the lowest $(33.2 \%)$.

\section{Data}

To assess the magnitude of EW seasonal mortality and morbidity by RHA monthly mortality and hospital admissions, data was collected. Mortality data is collected 


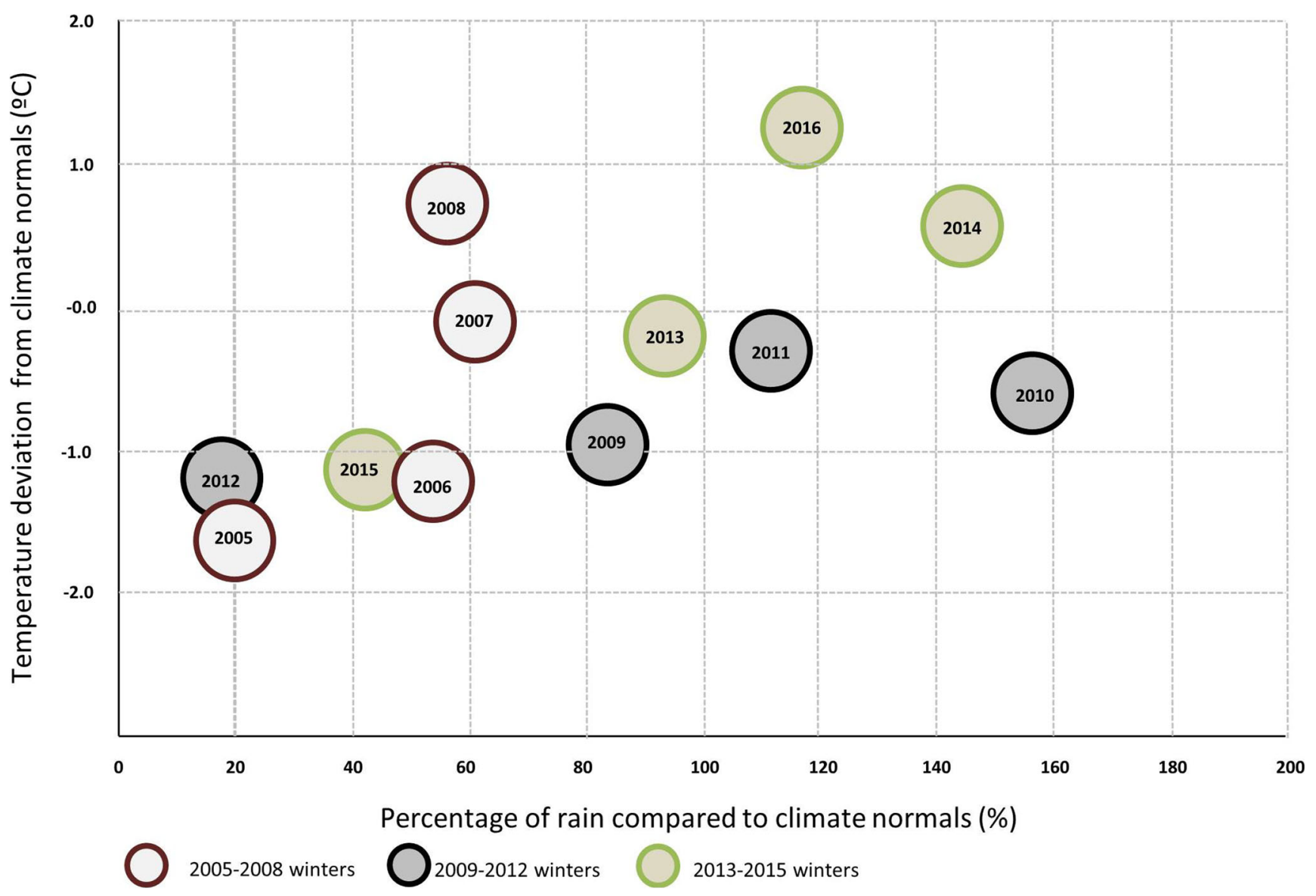

Fig. 2 Winter temperature and precipitation deviation from climate normal (2005 to 2015 winters). Adapted from IPMA (2018)

by the National Statistics Institute according to European Standards. Morbidity data is reported by public hospitals to the Central Administration of the Health System. The Central Administration of the Health System of the Portuguese Ministry of Health collects administrative and clinical data of all admissions to National Health hospitals, which covers almost the whole resident population of mainland Portugal (Froes et al. 2013). When the patient leaves the hospital, the admission record is created and classified according to national norms (e.g., diagnosis cause is attributed, release status, DRG group).

The number of deaths by all causes (International Classification of Diseases (ICD) 10: A00-Y89) was obtained from Statistics Portugal, and the number of emergency hospital admissions (all hospital admissions that are not planned in advance) in public hospitals (ICD9: 001-629; 760-E99 and ICD 10: A00-N99; P00-Y89) by all causes, except conditions related with pregnancy, childbirth, and puerperium, from the Central Administration of the Health System. Twelve years of data were collected and clustered into three 4-year periods: (i) Great Recession (2009-2012), (ii) PreRecession (2005-2008), and Post-Recession (20132016) (Table 1).

\section{Methods}

The number of EW deaths was calculated following the method proposed by Johnson and Griffiths (2003), which compares the number of winter deaths (December to March) with the average number of deaths in non-winter months (April to November). Monthly data were collected and normalized into standard 30-day months by multiplying the monthly number of deaths and emergency hospital admissions by the quotient resulting from the division between 30 and the number of days in the correspondent month. According to the Office for National Statistics (Office for National Statistics 2017), the EW death index is the ratio between the number of EW deaths and the average of non-winter deaths, multiplied by 100; it expresses the percentage of extra deaths that occurred in winter. The emergency EW hospital admissions number and index were estimated following the same method. The agestandardized EW death (hospitalizations) rate is calculated as a weighted average of the age-specific EW mortality (hospitalizations) rates per 100,000 persons, where the weights are the proportions of persons in the corresponding age groups of the European standard population.

The measurement of potential years of life lost (PYLL) is one of the most frequently used measures for monitoring the 
Table 1 Number of deaths and hospital admissions by period

\begin{tabular}{lll}
\hline Time periods & Total number of deaths & Total number of hospital admissions \\
\hline $2005-2008$ & 397,430 & $1,791,328$ \\
$2009-2012$ & 400,961 & $1,819,880$ \\
$2013-2016$ & 410,602 & $1,843,110$ \\
\hline
\end{tabular}

health of a population (Parrish 2010). It expresses the number of years that, theoretically, an individual will not live in the event of a premature death (deaths before reaching age 70); it differs from the standardized death rate, presented before, in that it assigns more weight to deaths occurring at younger ages (Mackenbach et al. 2013). The PYLL was calculated by multiplying the sum of the deaths in each age group by the number of years theoretically remaining (until reaching age 70 ). In the same way that this measure is calculated to measure the burden of specific causes of death, it can also be used with EW deaths. The excess winter PYLL rate is the quotient between average winter and non-winter PYLL.

Regular life tables summarize population mortality behavior, providing measures of longevity or life expectancy (Carey 1989) that are used to evaluate the general health status of a population (Santana and Nogueira 2001). The application of multiple decrement life tables allows the estimation of the likelihood of dying if the specific cause of death was reduced or eliminated (Preston et al. 2001) and, therefore, quantify the impact of that cause in life expectancy. To estimate the potential life expectancy gains if EW mortality would be reduced, multiple decrement life table was calculated as proposed by Macken and Chiang (1986) and Preston et al. (2001).

Rudge and Gilchrist (2007) state that addressing the impacts of cold on health through morbidity provides a different understanding of the phenomenon as it allows for the assessment of costs to and winter pressures on health services. Every hospital admission is clustered in a diagnosis-related group (DRG); each one has an official surcharge based on the pathology and complexity of treatment. Therefore, the costs of EW hospital admissions can be proxied by (1) identifying the number of EW hospitalizations in each DRG and (2) assigning to each EW hospital admission the prices defined by law (Ordinance 839-A/2009 (for 2005-2008), Ordinance 839-A/ 2009 (for the Great Recession period), and Ordinance 234/ 2015 (for 2013-2016)). This estimation did not consider the length of stay for the patients. The impact of the costs with EW hospital admissions was addressed by the rate of EW hospital admissions costs in the total hospitalizations costs.

All indicators were calculated for the entire country, for each of the three periods, and then replicated for each RHA, in order to evaluate within-country disparities and their trend.

Data availability Availability of data and material: Mortality datasets analyzed during the current study are available in National Statistics (www.ine.pt).
Morbidity data that support part of the findings of this study are available from Central Administration of the Health System, but restrictions apply to the availability of these data, which were used under license for the current study, and so are not publicly available. Data are, however, available from the Central Administration of the Health System upon request.

\section{Results}

\section{Mortality}

Four mortality measures were addressed to compare the EW mortality during the Great Recession (2009-2012) with the periods immediately before and after. In Portugal, winter deaths during the Great Recession were almost $30 \%$ higher than the number for non-winter mortality; this value was significantly (without overlapping confidence intervals) lower than that of the previous period and significantly higher than that of the following (EW death index in 2005-2008, 31.6\%; 2009-2012, 29.0\%; 2013-2016, 28.1\%) (Fig. 3a). This decreasing trend was common to all regions, except for Alentejo, where the EW mortality index increased in both the 2005-2008 and 2009-2012 periods. The highest values were recorded in the North RHA.

Following the same tendency, the standardized EW death rate was lower during the Great Recession period than in the Pre-Recession period, and higher than in the following (110 EW deaths per 100,000 inhabitants in 2005-2008, 90 during the Great Recession period, and 80 in 2013-2016) (Fig. 3b). Important disparities were found between RHAs, where, generally, high values are found in the Norte and LVT Regions, and low values in Algarve Region. Through the three periods, regional disparities increased: RHA with lower values improved more than the regions with higher standardized EW deaths.

With a similar evolution, the rate of EW PYLL slightly decreased between the first and the last period; there were 93 years of life lost per 100,000 inhabitants in 2005-2008, 87 years in 2009-2012, and 88 in the last period (Fig. 3c). Despite this decrease, the ratio between EW PYLL and nonwinter PYLL is increasing along the period under analysis (2005-2008, 9.9; 2009-2012, 10.9; 2013-2016, 12.6). Higher values were observed in the Alentejo and Norte RHAs, and lower values in the Algarve RHA. 
In 2005-2008, the life expectancy in Portugal was 81.42 years; if the EW deaths would have been totally avoided, life expectancy would have theoretically been prolonged by nearly 1 year, reaching 82.39 years (Fig. 3d). Like the other mortality measures, the results suggest a decreasing trend where the Great Recession is the intermediate period. Alentejo is the RHA where the decrease of excess winter deaths would have higher impacts on health expectancy.

\section{Morbidity}

In winter months, there were approximately $10 \%$ more hospitalizations than in the non-winter period; the highest winter increase was recorded in 2005-2008 (11.2\%) and has been decreasing since then $(9.6 \%$ and $9.2 \%$ during the Great Recession and in 2012-2016, respectively) (Fig. 4a). The RHA values are very irregular, changing significantly between periods; the highest values were recorded in LVT (20052008), Norte (2009-2012), and Alentejo (2013-2016).

In Portugal, nearly 55,000 EW hospital admissions were recorded during the Great Recession period, corresponding to 157 excess winter hospital admissions per 100.000 inhabitants (Fig. 4b); this value is intermediate with the period before and after (181 and 141 excess winter hospital admissions per 100,000 inhabitants, respectively). The standardized EW hospitalization rate decreased in all regions, except in Alentejo.

During the Great Recession, the costs in terms of EW hospitalizations were at their lowest value. In 2009-2012, excess winter admission costs an additional 214 million euros, representing $4.4 \%$ of the total costs with hospital admissions. In 2005-2008, the cost estimation was of 226 million euros (4.7\% of the total cost) and in 2013-2016 was of 227 million euros $(5.9 \%)$ (Fig. 4c). The highest values were recorded in Algarve Region in 2013-2016, where nearly 7\% of the total costs are due to EW hospitalizations. In 2009-2012, the estimation of EW hospitalizations costs per number of hospitalization was, on average, 2749 euros, being higher in Alentejo (2842 euros) and Algarve (3057 euros).

\section{Discussion}

\section{Summary of findings}

This study compares several measures of EW mortality and morbidity during the Great Recession (2009-2012) with the periods preceding and following. It identified important winter increases of deaths and hospital admissions resulting in an important amount of PYLL, life expectancy loss, and National Health Service costs with explicit temporal and spatial variations. These human and economic costs did not increase during the Great Recession, and, except for the EW hospitalization costs, a consistent decrease was found during the periods analyzed. Although common to all RHAs, the EW mortality and morbidity varies between regions. From the assessment of the EW mortality indicators, Norte and Alentejo RHAs were identified as having higher winter mortality burdens in all indicators. The morbidity indicator pattern is marked by higher variability: Centro shows higher winter increase of emergency hospitalizations; the standardized EW hospitalization rate is larger at Norte RHA; and Algarve has the highest cost with increased EW hospitalizations. The evolution of the RHA EW mortality and morbidity indicators is in conformity with country level patterns.

\section{Comparison with previous work}

Despite the decreasing trend, the winter excess mortality burden in Portugal is still extremely high. During the Great Recession period, the EW mortality index was $29 \%$, while in England and Wales, according to the Office for National Statistics, it was almost half (16.8 in the winter of 2009/2010, 16.9 in 2010/2011, and 15.5 in 2011/2012); the magnitude of these values is in conformity with previous studies assessing excess winter mortality in Portugal (Healy 2003; Fowler et al. 2015; Almendra et al. 2016). Benmarhnia et al. (2014) found in a study addressing the seasonal mortality trends in the years before and after the Great Recession in Spain that the winter mortality increase was systematically more pronounced during the crisis than before the crisis. The measurement of the impact of winter mortality in life expectancy or the number of excess winter PYLL is not often estimated; therefore, the comparison of Portugal with other countries was not possible.

Evidence showed that excess winter morbidity and mortality resulted in additional pressure on hospitals, primary care settings, and other health services (NICE 2015). There were around $10 \%$ more emergency hospital admissions in the winter period compared with the average of non-winter months. This pattern of winter increase in hospital admissions was also found by several authors analyzing diseases of the respiratory and circulatory systems (Maheswaran et al. 2004; Rudge and Gilchrist 2005). The EW hospitalizations resulted in a cost increase of $4.5 \%$, close to values found in Yorkshire and the Humber Region in the UK (Bland et al. 2015). The reduced EW hospitalization rate and costs during the economic crisis may result from the impact of the Economic Adjustment Programme on public hospital financing, which imposed severe budget cuts, possibly explaining the reduction of expenditures during that period.

Regional disparities are often found when addressing the impacts of seasonal winter mortality, even when assessing regions from the same country with similar climate (Hajat et al. 2006). The RHA differences found in this study are generally in accordance with the results from previous work 
a

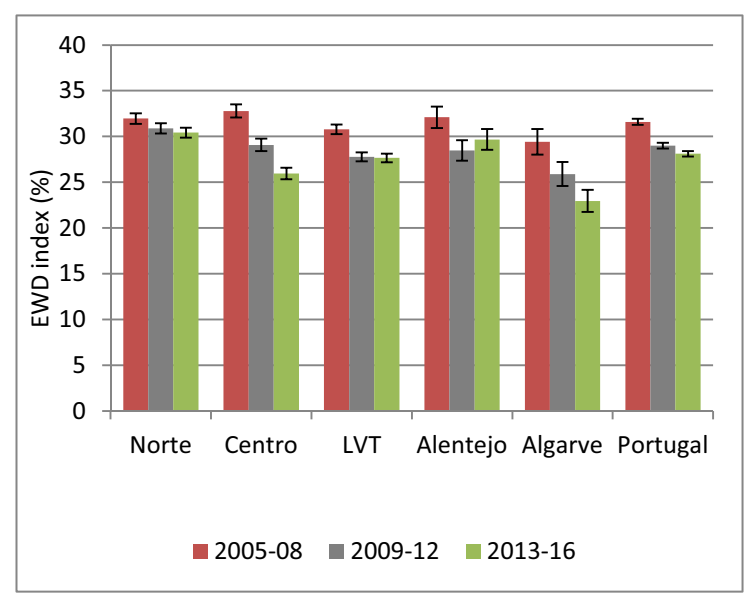

C

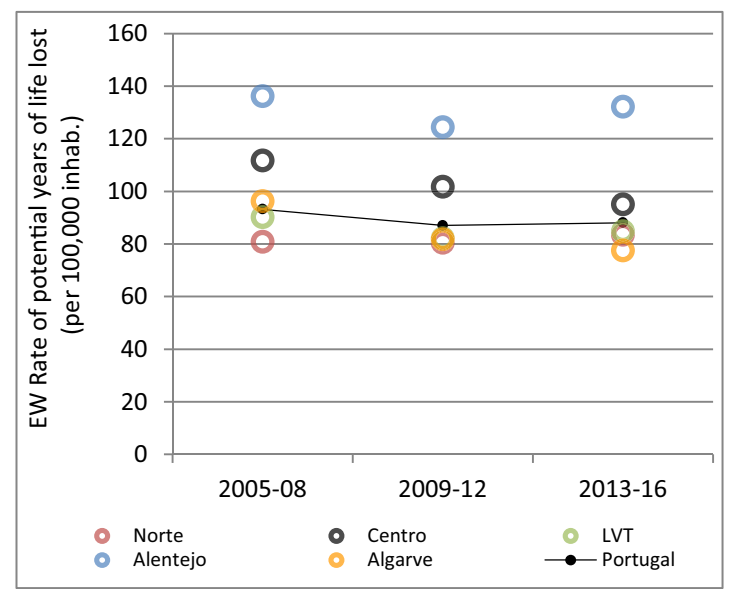

b

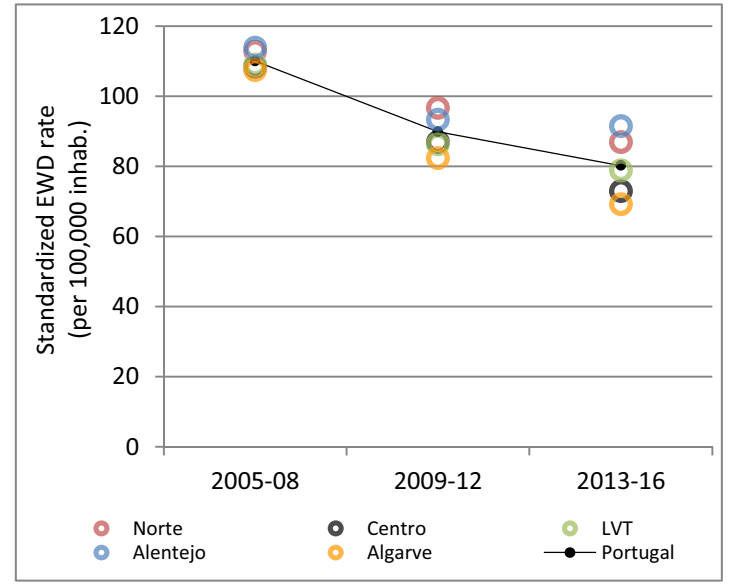

d

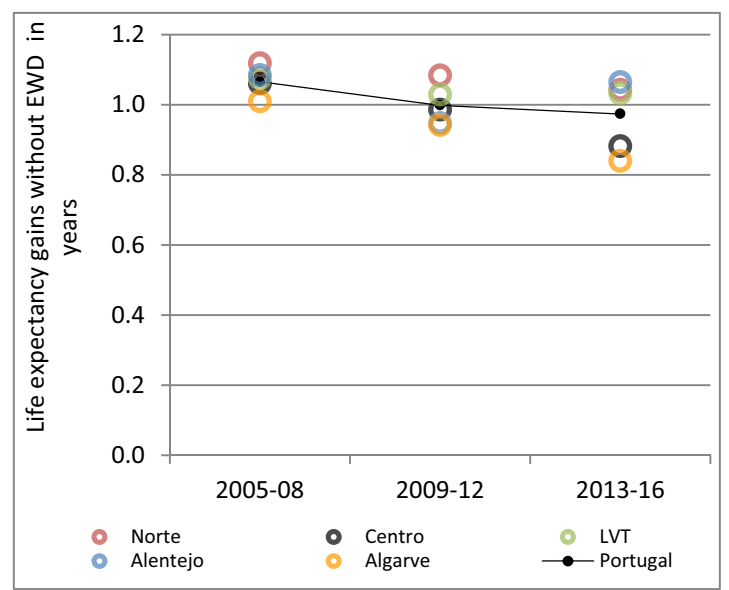

Fig. 3 Excess winter mortality measures by Regional Health Administration (a: Excess Winter Deaths index; b: Standardized Excess Winter Deaths rate; c: Excess Winter Rate id potential years of life lost; $\mathbf{d}$ : Life expectancy gains without Excess Winter Deaths)

assessing the geographical seasonal mortality patterns in Portugal (Almendra et al. 2016).

\section{Factors influencing annual and regional variations}

Similar to most European countries, Portugal is exhibiting a long trend in terms of mortality decrease. This evolution must be taken into account when considering certain mortality measures, such as the standardized EW mortality rates or PYLL, once it is possible that the observed decrease may be related to the long-term trend (Benmarhnia et al. 2014; Tapia Granados and Rodriguez 2015).

The inter-annual variation of EW mortality observed in this study may have been influenced by several environmental (e.g., winter temperature, air quality) and epidemiological (e.g., influenza) factors (Conlon et al. 2011; Phu Pin et al. 2012; Vestergaard et al. 2017), although according to Fowler et al. (2015), the relative influence of this factors is still to be estimated. This would require indeed microdata with information on lifelong exposure to adverse effects, which is far beyond the scope of this study.

The winters of 2005, 2006, 2012, and 2015 were classified as colder than the normal (between one and two degrees colder) and the winters of 2008 and 2016 as warmer than the normal (between half and two degrees warmer); normal is referred to as the climate normal of 1971-2000 (IPMA 2018). The influenza severity data are only available after 2007; the winters between 2009 and 2012 were marked by a high incidence rate of flu syndrome, and in the period after the Great Recession, only the winter of 2015 had high incidence rate (INSA 2017). Moreover, Monteiro et al. (2018) identified a significant improvement in air quality in Portugal, directly related to the reduction of energy consumption as a consequence of the economic crisis. The characterization of these factors may help to understand the evolution of excess winter mortality and morbidity, offering a possible explanation for the lower EW mortality during the Great Recession, i.e., that the less severe winters compensated the more difficult socioeconomic conditions. 
a

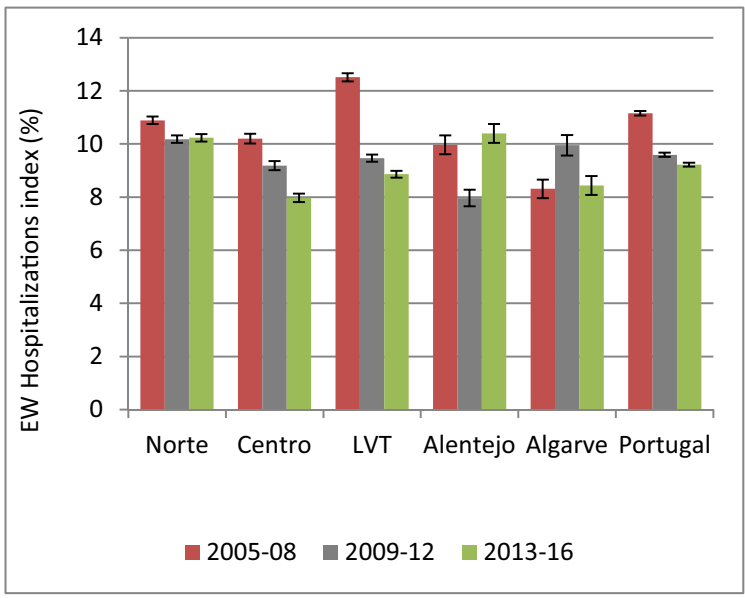

c

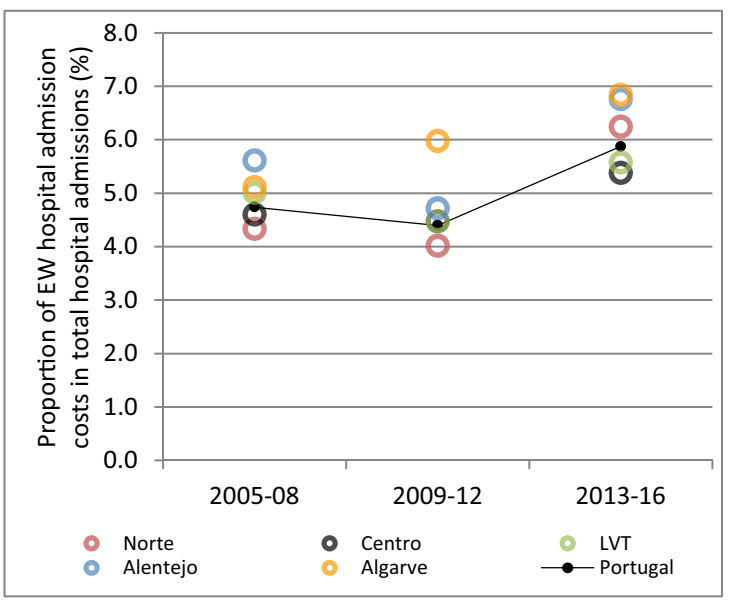

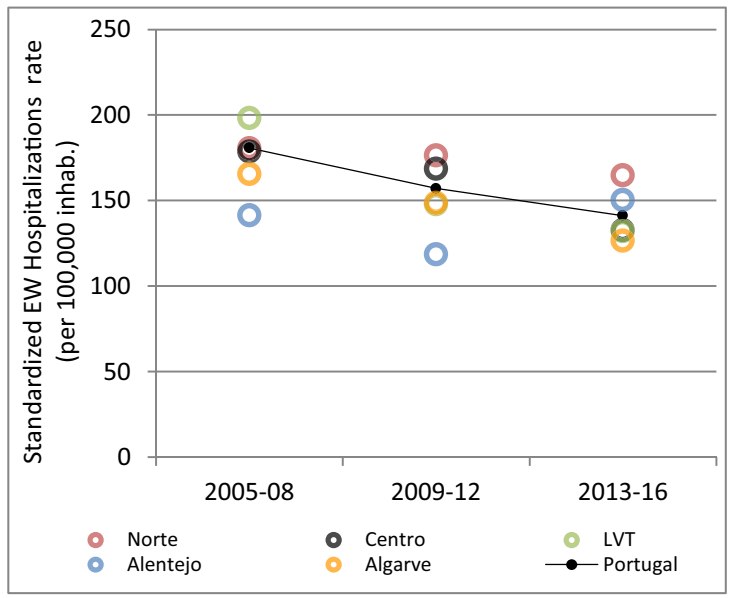

Fig. 4 Excess winter hospital admission measures by Regional Health Administration (a: Excess Winter Hospitalizations index; b: Standardized Excess Winter Hospitalizations rate; c: Proportion of Excess Winter hospitalizations costs in total hospital admissions)

By assessing the regional disparities, Alentejo is the RHA with the worst performance in all the EW mortality indicators. Individual and contextual conditions such as aging and housing characteristics are important factors to explain these results. Alentejo is the region with both the highest aging ratio (according to Statistics Portugal, the Aging ratio in 2011 was 189 in Alentejo, whereas the country average was 130) and the worst housing conditions (Almendra et al. 2017). A lower winter mortality burden was found in Algarve, which may also be related to the particular climatic conditions of Algarve Region (being Portugal's southern-most, its average yearly temperatures are warmer than in the other four regions).

\section{Excess winter mortality and morbidity during and after the Great Recession}

Several authors found associations between poor socioeconomic conditions and EW mortality and morbidity (Healy 2003; Howieson and Hogan 2005; Hales et al. 2012; Marmot and Bell 2012; Almendra et al. 2017; Marí-
Dell'Olmo et al. 2018). The results presented in our study indicate that the aggravation of socioeconomic conditions during the Great Recession did not coincide with significantly higher winter increases in mortality and morbidity, when compared to the other periods under analysis. Numerous reasons may have contributed to these results. Basic healthcare has resisted the crisis quite well and may have played an important role in providing health support to the population; Dimitrovová and Perelman (2018) state that in Portugal, the probability of reporting difficulties in accessing primary care services was $10.8 \%$ lower in 2012 , in comparison with 2007. Rolden et al. (2014) found that downward cycles in economy are coincident with mortality decreases; the winter mortality results may also be influenced by this trend.

The incapacity of maintaining adequate thermal comfort indoors during winter is most likely to be the key determinant for exposure to cold weather (Vasconcelos et al. 2011), and therefore, the response given to extreme cold events may probably only address a part of the cold-related illnesses. 
Measures to prevent indoor exposure to cold during prolonged periods can be achieved through the improvement of housing insulation combined with efficient heating devices (Dear and McMichael 2011). It thus becomes necessary to consider the Eurostat data which express how the price of electricity in Portugal has increased 70\% from 2005 to 2016 (during the Great Recession, it increased 30\%) and nearly half of the housing units equipped with heating systems use electricity as the main source of energy. The price growth of electricity may have resulted in higher vulnerability to cold weather for an important number of socially vulnerable households, even if the EW mortality and morbidity did not increase.

The EW mortality and morbidity during the last period (2013-2016) might have been minimized by several multilevel cold weather response plans. The current Portuguese Contingency Seasonal Health Plan-Winter Module is active from November to March and in periods of extreme cold aims to minimize the negative effects of extreme cold and respiratory infections (Direcção-Geral da Saúde 2017). According to Hajat et al. (2016), assessing the development of Public Health England's Cold Weather Plan, the all-year planning for cold weather (levels 0 , year-round planning) and the winter preparedness phase (level 1 , winter preparedness and action) are crucial components in comparison to the alerts to minimize the vulnerability to cold.

Improving the understanding of the effects of the economic crisis on the vulnerability to seasonal cold weather is an important step towards prevention of possible avoidable human and economic costs (Benmarhnia et al. 2014). Even though this study contributes to that understanding, further studies addressing the impact of economic crisis in the vulnerability to cold weather are still needed.

\section{Limitations}

This study aims to measure the seasonal winter mortality and morbidity during the Great Recession and not to assess its impacts on the evolution of EW mortality and morbidity, which would require detailed microdata on socioeconomic changes and health outcomes.

This study compares several morbidity and mortality measures in different periods on a RHA scale. It is possible that the time periods are too short to capture the full influences of the economic recession (Zapata Moya et al. 2015). A longer observation period would permit to determine whether there have been substantial modifications in the time trend during the economic crisis, possibly allowing the causality measurement. At the same time, the scale of analysis hides subregional patterns and socioeconomic disparities as well as different responses to the economic recession. Different regional and temporal patterns could have been found if the analysis would have been stratified by cause of death. Moreover, despite the partial change in the hospital classification from ICD 9 to ICD 10 during the last year under analysis, the yearly variation of hospital admissions was very small.

The inter-annual variations of EW mortality and morbidity are strongly influenced by environmental and epidemiological factors. The access to seasonal influenza data by RHA would have been useful to identify the inter-annual epidemic pattern and to compare it with our results. Moreover, the understatement of current results would have been improved by the access to winter temperature.

Cyclical trends in hospital admissions and also in mortality, related to days, months, and seasons, are well known. However, our study was not designed to model such effects, but, on the contrary, to compare values across longer periods.

\section{Conclusions}

This work found that in Portugal, the winter increases in mortality and morbidity were not higher during the Great Recession. Nevertheless, the degree of excess winter mortality and morbidity resulting in potential avoidable years of life lost, lower life expectancy, and costs to the National Health System was found to be extremely high in Portugal. Although on a different scale, this phenomenon is common to all regions.

This study draws attention to the extent of excess winter mortality and morbidity and its evolution during the Great Recession period in Portugal. It highlights the necessity of a better understanding on excess winter mortality and morbidity determinants, in order to implement more effective mitigation strategies.

Authors' contributions RA, PS, JP, and JV contributed to the study conception and design. RA was responsible for the acquisition of data. RA, PS, JP, and JV contributed to the analysis and interpretation of data. RA was responsible for drafting of manuscript. RA, PS, JP, and JV contributed to the critical revision and final version of the manuscript.

Funding RA and PS are part of CEGOT, Research Centre in Geography and Spatial Planning, that is supported by the European Regional Development Funds, through the COMPETE 2020 - Operational Programme "Competitiveness and Internationalization," under Grant POCI-01-0145-FEDER-006891; and by National Funds through the Portuguese Foundation for Science and Technology (FCT) under Grant UID/GEO/04084/2013. RA was funded by FCT doctoral fellowship SFRH/BD/92568/2013 and by the CEGOT group Cities, competitiveness, and well-being (UID/GEO/04084/2013) through COMPETE 2020.

\section{Compliance with ethical standards}

Ethics approval and consent to participate Not applicable.

Consent for publication Not applicable.

Competing interests The authors declare that they have no competing interests. 
Authors' information (optional) Not applicable.

\section{References}

Almendra R, Santana P, Freire E, Vasconcelos J (2016) Seasonal mortality patterns and regional contrasts in Portugal. Bull Geogr 32:7-18. https://doi.org/10.1515/bog-2016-0011

Almendra R, Santana P, Vasconcelos J (2017) Evidence of social deprivation on the spatial patterns of excess winter mortality. Int J Public Health 62:849-856. https://doi.org/10.1007/s00038-017-0964-7

Antunes L, Silva SP, Marques J, Nunes B, Antunes S (2017) The effect of extreme cold temperatures on the risk of death in the two major Portuguese cities. Int J Biometeorol 61:127-135. https://doi.org/ 10.1007/s00484-016-1196-X

Benmarhnia T, Zunzunegui M-V, Llacer A, Beland F (2014) Impact of the economic crisis on the health of older persons in Spain: research clues based on an analysis of mortality. SESPAS report 2014. Gac Sanit 28(Suppl 1):137-141. https://doi.org/10.1016/j.gaceta.2014. 02.016

Bland D, Lewis J, Kemp N (2015) Joint strategic needs assessment. Winter health. North Yorkshire

Carey JR (1989) The multiple decrement life table: a unifying framework for cause-of-death analysis in ecology. Oecologia 78:131-137. https://doi.org/10.1007/BF00377208

Conlon KC, Rajkovich NB, White-Newsome JL, Larsen L, O'Neill MS (2011) Preventing cold-related morbidity and mortality in a changing climate. Maturitas 69:197-202

Davie GS, Baker MG, Hales S, Carlin JB (2007) Trends and determinants of excess winter mortality in New Zealand: 1980 to 2000 . BMC Public Health 7:263. https://doi.org/10.1186/1471-2458-7-263

Dear KBG, McMichael AJ (2011) The health impacts of cold homes and fuel poverty. In: The health impacts of cold homes and fuel poverty. England, London

Dimitriou K, McGregor GR, Kassomenos PA et al (2016) Exploring winter mortality variability in five regions of England using back trajectory analysis. Earth Interact 20:1-27. https://doi.org/10.1175/ EI-D-15-0012.1

Dimitrovová K, Perelman J (2018) Changes in access to primary care in Europe and its patterning, 2007-12: a repeated cross-sectional study. Eur J Pub Health 28:1-7. https://doi.org/10.1093/eurpub/cky019

Direcção-Geral da Saúde (2017) PLANO DE CONTINGÊNCIA SAÚDE SAZONAL - MÓDULO INVERNO. Lisboa

Doetsch J, Pilot E, Santana P, Krafft T (2017) Potential barriers in healthcare access of the elderly population influenced by the economic crisis and the troika agreement: a qualitative case study in Lisbon, Portugal. Int J Equity Health 16:184. https://doi.org/10. 1186/s12939-017-0679-7

European Commission (2014) The Economic Adjustment Programme for Portugal 2011-2014. Brussels

Fowler T, Southgate RJ, Waite T, Harrell R, Kovats S, Bone A, Doyle Y, Murray V (2015) Excess winter deaths in Europe: a multi-country descriptive analysis. Eur J Pub Health 25:339-345. https://oi.org/ 10.1093/eurpub/cku073

Frasquilho D, Matos MG, Salonna F, Guerreiro D, Storti CC, Gaspar T, Caldas-de-Almeida JM (2015) Mental health outcomes in times of economic recession: a systematic literature review. BMC Public Health 16:115. https://doi.org/10.1186/s12889-016-2720-y

Freire E (1996) The comfort climatology of Portugal, a contribution to human bioclimatology. Dissertação de Doutoramento. Universidade de Londres

Froes F, Diniz A, Mesquita M, Serrado M, Nunes B (2013) Hospital admissions of adults with community-acquired pneumonia in Portugal between 2000 and 2009. Eur Respir J 41:1141-1146. https://doi.org/10.1183/09031936.00216711
Hajat S, Chalabi Z, Wilkinson P, Erens B, Jones L, Mays N (2016) Public health vulnerability to wintertime weather: time-series regression and episode analyses of national mortality and morbidity databases to inform the Cold Weather Plan for England. Public Health 137:2634. https://doi.org/10.1016/j.puhe.2015.12.015

Hajat S, Kovats RS, Lachowycz K (2006) Heat-related and cold-related deaths in England and Wales: who is at risk? Occup Environ Med 64:93-100. https://doi.org/10.1136/oem.2006.029017

Hales S, Blakely T, Foster RH, Baker MG, Howden-Chapman P (2012) Seasonal patterns of mortality in relation to social factors. J Epidemiol Community Health 66:379-384. https://doi.org/10. 1136/jech.2010.111864

Healy JD (2003) Excess winter mortality in Europe: a cross country analysis identifying key risk factors. J Epidemiol Community Health 57:784-789. https://doi.org/10.1136/jech.57.10.784

Howieson SG, Hogan M (2005) Multiple deprivation and excess winter deaths in Scotland. J R Soc Promot Heal 125:18-22. https://doi.org/ $10.1177 / 146642400512500110$

INSA (2017) Boletim de Vigilância Epidemiológica da Gripe. Época 2016/2017. Lisboa

IPMA (2018) Boletim Climatológico Sazonal. Inverno 2015/16. Lisboa

Johnson H, Griffiths C (2003) Estimating excess winter mortality in England and Wales. Health Stat Q 20:19-24

Karanikolos M, Mladovsky P, Cylus J, Thomson S, Basu S, Stuckler D, Mackenbach JP, McKee M (2013) Financial crisis, austerity, and health in Europe. Lancet (London, England) 381:1323-1331. https://doi.org/10.1016/S0140-6736(13)60102-6

Keatinge WR (1997) Cold exposure and winter mortality from ischaemic heart disease, cerebrovascular disease, respiratory disease, and all causes in warm and cold regions of Europe. Lancet 349:13411346. https://doi.org/10.1016/S0140-6736(96)12338-2

Legido-Quigley H, Karanikolos M, Hernandez-Plaza S, de Freitas C, Bernardo L, Padilla B, Sá Machado R, Diaz-Ordaz K, Stuckler D, McKee M (2016) Effects of the financial crisis and troika austerity measures on health and health care access in Portugal. Health Policy (New York) 120:833-839. https://doi.org/10.1016/J.HEALTHPOL. 2016.04.009

Liddell C, Morris C, Thomson H, Guiney C (2016) Excess winter deaths in 30 European countries 1980-2013: a critical review of methods. J Public Heal (United Kingdom) 38:806-814

Macken CA, Chiang C (1986) The life table and its applications, R.E. Krieg. R.E. Krieger Pub. Co., Malabar, Florida

Mackenbach J, Karanikolos M, McKee M (2013) Past and future health gains. In: Mackenbach J, McKee M (eds) Successes and failures of health policy in Europe: four decades of divergent trends and converging challenges, Open Unive. Berkshire, pp 256-284

Maheswaran R, Chan D, Fryers PT, McManus C, McCabe H (2004) Socio-economic deprivation and excess winter mortality and emergency hospital admissions in the South Yorkshire Coalfields Health Action Zone, UK. Public Health 118:167-176. https://doi.org/10. 1016/j.puhe.2003.09.004

Marí-Dell'Olmo M, Tobías A, Gómez-Gutiérrez A, Rodríguez-Sanz M, García de Olalla P, Camprubí E, Gasparrini A, Borrell C (2018) Social inequalities in the association between temperature and mortality in a South European context. Int J Public Health 64:27-37. https://doi.org/10.1007/s00038-018-1094-6

Marmot M, Bell R (2012) Fair society, healthy lives. Public Health 126: S4-S10. https://doi.org/10.1016/j.puhe.2012.05.014

Mercer JB (2003) Cold - an underrated risk factor for health. Environ Res 92:8-13. https://doi.org/10.1016/S0013-9351(02)00009-9

Monteiro A, Russo M, Gama C, Lopes M, Borrego C (2018) How economic crisis influence air quality over Portugal (Lisbon and Porto)? Atmos Pollut Res 9:439-445. https://doi.org/10.1016/J.APR.2017. 11.009

NICE (2015) Excess winter deaths and illness and the health risks associated with cold homes $\mid$ guidance and guidelines $\mid$ NICE. NICE 
Nogueira P, Paixão E (2007) Sazonalidade e periodicidades da mortalidade portuguesa 1980 a 2001, Fundação M. Fundação Merck Sharp Dohme, Lisboa

Office for National Statistics (2017) Excess winter mortality in England and Wales: 2016 to 2017 (provisional) and 2015 to 2016. London

Ou CQ, Song YF, Yang J, Chau PYK, Yang L, Chen PY, Wong CM (2013) Excess winter mortality and cold temperatures in a Subtropical City, Guangzhou, China. PLoS One 8. https://doi.org/ 10.1371/journal.pone.0077150

Parrish RG (2010) Measuring population health outcomes. Prev Chronic Dis 7:A71-A45. https://doi.org/10.1377/hlthaff.28.1.42

Perelman J, Felix S, Santana R (2015) The great recession in Portugal: impact on hospital care use. Health Policy (New York) 119:307315. https://doi.org/10.1016/j.healthpol.2014.12.015

Phu Pin S, Golmard JL, Cotto E, Rothan-Tondeur M, Chami K, Piette F (2012) Excess winter mortality in France: influence of temperature, influenza like illness, and residential care status. J Am Med Dir Assoc 13:309.e1-309.e7. https://doi.org/10.1016/j.jamda.2011.06. 005

Pinheiro CDFB (1990) Um frio de morrer ou a variação da mortalidade e clima nos distritos de Viana do Castelo e de Faro. Arq do Inst Nac Saúde:61-112

Preston SH, Heuveline P, Guillot M (2001) Demography: measuring and modeling population processes. Wiley

Rau R (2004) Seasonality in human mortality. In: A demographic approach. Springer, Berlin

Regidor E, Barrio G, Bravo MJ, De La Fuente L (2014) Has health in Spain been declining since the economic crisis? J Epidemiol Community Health 68:280-282. https://doi.org/10.1136/jech2013-202944

Rolden HJA, van Bodegom D, van den Hout WB, Westendorp RGJ (2014) Old age mortality and macroeconomic cycles. J Epidemiol Community Health 68:44-50. https://doi.org/10.1136/jech-2013202544

Rudge J, Gilchrist R (2007) Measuring the health impact of temperatures in dwellings: investigating excess winter morbidity and cold homes in the London Borough of Newham. Energy Build 39:847-858. https://doi.org/10.1016/j.enbuild.2007.02.007

Rudge J, Gilchrist R (2005) Excess winter morbidity among older people at risk of cold homes: a population-based study in a London borough. J Public Health (Bangkok) 27:353-358. https://doi.org/10. 1093/pubmed/fdi051

Santana P, Nogueira H (2001) A Esperança de Vida em Portugal. Cad Geogr:3-13

Sartini C, Barry SJE, Wannamethee SG, Whincup PH, Lennon L, Ford I, Morris RW (2016) Effect of cold spells and their modifiers on cardiovascular disease events: evidence from two prospective studies. Int J Cardiol 218:275-283. https://doi.org/10.1016/j.ijcard.2016.05. 012

Tapia Granados JA, Rodriguez JM (2015) Health, economic crisis, and austerity: a comparison of Greece, Finland and Iceland. Health Policy (New York) 119:941-953

Vasconcelos J, Freire E, Morais J, Machado JR, Santana P (2011) The health impacts of poor housing conditions and thermal discomfort. Procedia Environ Sci 4:158-164. https://doi.org/10.1016/j.proenv. 2011.03.019

Vestergaard LS, Nielsen J, Krause TG, Espenhain L, Tersago K, Bustos Sierra N, Denissov G, Innos K, Virtanen MJ, Fouillet A, Lytras T, Paldy A, Bobvos J, Domegan L, O’Donnell J, Scortichini M, de Martino A, England K, Calleja N, van Asten L, Teirlinck AC, Tønnessen R, White RA, P Silva S, Rodrigues AP, Larrauri A, Leon I, Farah A, Junker C, Sinnathamby M, Pebody RG, Reynolds A, Bishop J, Gross D, Adlhoch C, Penttinen P, Mølbak K (2017) Excess all-cause and influenza-attributable mortality in Europe, December 2016 to February 2017. Eurosurveillance 22. https://doi.org/10.2807/1560-7917.ES.2017.22.14.30506

Zapata Moya AR, Buffel V, Navarro Yáñez CJ, Bracke P (2015) Social inequality in morbidity, framed within the current economic crisis in Spain. Int J Equity Health 14. https://doi.org/10.1186/s12939-015$0217-4$ 